\title{
Peran Masyarakat Dalam Pengelolaan Ekominawisata Pulau Lusi, Kabupaten Sidoarjo
}

\author{
Yanelis Prasenja \\ Program Studi Ilmu Lingkungan, Sekolah Ilmu Lingkungan, Universitas Indonesia, Jakarta, Indonesia \\ Email Koresponden: prasenja@yahoo.com
}

Diterima: Mei 2018 /Refisi: Mei 2018 Disetujui: September 2018

๑ 2018 Fakultas Geografi UGM dan Ikatan Geograf Indonesia (IGI)

\begin{abstract}
Abstrak Potensi dan keunikan sumber daya alam pada kawasan ekosistem mangrove di Pulau Lusi jika dikelola dengan baik dapat memiliki peran yang signifikan dalam pengembangan ekonomi, sosial, budaya dan lingkungan masyarakat kawasan Pulau Lusi. Pulau Lusi merupakan pulau buatan yang dibentuk sebagai solusi dari penanganan endapan sedimen di Muara Sungai Porong akibat dari semburan panas yang dialirkan ke laut melalui Sungai Porong. Saat ini Pulau Lusi dimanfaatkan sebagai lahan untuk menambah luasan ekosistem mangrove di muara dan perikanan budidaya dengan sistem wanamina (Silvofishery). Ekominawisata merupakan salah satu pemanfaatan ekosistem mangrove dan tambak wanamina dengan pendekatan edukasi dan ekonomi untuk mencapai kesejahteraan masyarakat. Selain itu, ekominawisata ini secara langsung memiliki manfaat pelestarian alam dan lingkungan. Pengelolaan ekominawisata di Pulau Lusi tidak sepenuhnya menjadi tanggung jawab pemerintah melalui Kementerian Kelautan dan Perikanan akan tetapi diperlukan peran serta masyarakat di kawasan Pulau Lusi untuk mencapai kelestarian ekosistem mangrove dan kesejahteraan masyarakat. Tujuan penelitian adalah untuk menilai potensi ekominawisata di Pulau Lusi. Metode yang digunakan adalah gabungan antara metode kuantitatif dan kualitatif. Pengambilan data berupa kuesioner, wawancara, observasi, kajian literatur dan dokumentasi. Hasil penelitian menunjukkan bahwa 1) sumber daya alam di Pulau Lusi sesuai untuk dikembangkan dan dimanfaatkan sebagai kawasan ekominawisata, dan 2) adanya partisipasi masyarakat melalui kelembagaan swadaya masyarakat menjadi modal utama dalam upaya pengelolaan dan pengembangan ekominawisata Pulau Lusi.
\end{abstract}

Kata kunci: ekominawisata, mangrove, partisipasi masyarakat, pulau lusi

\begin{abstract}
Potential and uniqueness of natural resources in Lusi Island mangrove ecosystem area have a significant role in community economical, socio-cultural and environmental development if it's managed properly. Lusi Island is an artificial island created as a solution to the handling of sediment deposition in Porong River Estuary as a result of the mudflow which flowed into the sea via the Porong River. Lusi Island is currently utilized as a habitat for mangrove ecosystem extension as well as a site for aquaculture with wanamina system (silvofishery). Ecofisherytourism is a way to utilize mangrove ecosystem for ponds silvofishery based on educational and economic approach to achieve the welfare of society. In addition, eco-fisherytourism has a direct benefit of preserving nature and the environment. Eco-fisherytourism management in Lusi Island not only becomes government responsibility particularly Ministry of Marine Affairs and Fisheries but also becomes community responsibilty to participate and to achieve sustainability of mangrove ecosystem and community welfare. The objective of this study is to assess the potential of ecotourism in Sidoarjo mud flat. The method used is a combination of quantitative and qualitative methods. Data collection by using questionnaires, interviews, observation, literature review and documentation. The result of the research shows that 1) natural resources in Lusi Island are suitable to be developed and to be utilized as an eco-tourism area, and 2) the participation of community through self-supporting institutionhave becoming the main capital in managing and developing Lusi Island eco-fisherytorism.
\end{abstract}

Keywords : eco-fisherytorism, mangrove, community participation, lusi island

\section{PENDAHULUAN}

Pulau Lusi yang sedang didaftarkan ke PBB awal tahun 2018 berada di muara sungai Porong, Sidoarjo. Pulau Lusi terbentuk dari hasil pengerukan endapan sedimen lumpur seluas \pm 94 ha, dengan letak koordinat $7 \quad 34024.1^{\circ} \mathrm{LS} 11252^{\prime} 49.7^{\circ} \mathrm{BT}$. Bentukan tersebut diharapkan dapat dimanfaatkan untuk menambah luasan ekosistem mangrove di muara demikian juga lahan budidaya dengan sistem sylvofishery (BPLS dan BPOL, 2012). Wilayah pesisir dengan karakteristik substrat berlumpur menjadi habitat utama dari ekosistem mangrove di Indonesia. Wilayah ini dikenal sarat dengan keindahan dan sekaligus konflik kepentingan, sehingga ekosistem di wilayah tersebut menghadapi berbagai ancaman dan masalah perusakan yang diakibatkan oleh manusia (Apriana, 2015).

Kerusakan ekosistem mangrove terjadi hampir di seluruh kawasan pesisir Indonesia, salah satunya di wilayah pesisir Kabupaten Demak Jawa Tengah. Menurut data dari Dinas Kelautan dan Perikanan Kabupaten Demak, pada tahun 2011 luas ekosistem mangrove di Kabupaten Demak sekitar 8\% dalam kondisi rusak, dan dari hasil penelitian yang dilakukan oleh Faturrohmah dan Marjuki (2017) bahwa dalam 
kurun waktu lima tahun terakhir (2010-2015), distribusi spasial dan luasan hutan mangrove di wilayah pesisir Kabupaten Demak secara umum tidak mengalami perubahan yang besar, yaitu hanya mengalami penurunan seluas 68,17 ha.

Kondisi tersebut tidak jauh berbeda dengan yang terjadi pada kawasan mangrove di Kabupaten Sidoarjo. Luas ekosistem mangrove di pesisir Sidoarjo semakin berkurang. Hasil penelitian yang dilakukan oleh Hidayah dan Wijayanto (2013) menunjukkan bahwa dari hasil analisis citra Landsat tahun 2002 dan 2010 terlihat ekosistem mangrove di Kabupaten Sidoarjo telah mengalami pengurangan luas total dari 1.236,42 ha menjadi $1.203,35$ ha. Wilayah yang mengalami penurunan luas ekosistem mangrove terbesar di Kabupaten Sidoarjo adalah Kecamatan Jabon, yaitu sebesar 55,94 ha. Kerusakan ekosistem mangrove di Kabupaten Sidoarjo lebih banyak disebabkan oleh aktivitas penebangan liar (illegal logging) dan adanya konversi ekosistem mangrove menjadi lahan tambak oleh masyarakat setempat.

Kawasan ekosistem mangrove di Pulau Lusi Sidoarjo memiliki potensi dan keunikan sumberdaya alam yang dapat dimanfaatkan dan dikelola secara optimal, bijaksana dan berkelanjutan demi tercapainya kesejahteraan masyarakat disekitar Pulau Lusi. Salah satu pemanfaatan ekosistem mangrove dan tambak wanamina yang berada di Pulau Lusi dengan pendekatan edukasi dan ekonomi untuk mencapai kesejahteraan masyarakat melalui kegiatan pariwisata adalah ekominawisata.

Kunjungan wisatawan ke dermaga Tlocor tidak kurang dari 50 orang pada hari Sabtu dan Minggu (Mulyo, 2015). Atraksi wisata yang ditawarkan yaitu wisatawan dapat menyusuri Sungai Porong hingga ke bagian muara dimana terdapat Pulau Lusi yang merupakan kawasan konservasi mangrove, menikmati sunset atau sunrise serta memancing. Prasenja, et al (2017) menyatakan kegiatan konservasi di pulau Lumpur Sidoarjo memiliki potensi untuk dimanfaatkan sebagai kawasan wisata alam dan perikanan (ekominawisata) agar dapat meningkatkan pendapatan masyarakat sekitar, sehingga masyarakat termotivasi untuk melestarikan mangrove.

Pengelolaan ekominawisata di Pulau Lumpur Sidoarjo tidak sepenuhnya menjadi tanggung jawab pemerintah melalui Kementerian Kelautan dan Perikanan akan tetapi diperlukan peran serta masyarakat di kawasan Pulau Lusi. Dengan melibatkan peran serta masyarakat dalam pengelolaan ekowisata memberikan pelajaran sekaligus panggung kepada masyarakat untuk ikut serta menjaga kelestarian kawasan wisata (Bickford, et al, 2017) melalui kegiatan pembibitan, penanaman dan rehabilitasi kembali kawasan mangrove yang rusak (Dianawati, et al, 2014) menjadi sebuah budaya. Dengan demikian diharapkan adanya keharmonisan dalam pengelolaan ekominawisata Pulau Lusi secara terpadu antara lembaga pemerintah dengan lembaga masyarakat sehingga kesejahteraan masyarakat sekitar kawasan akan tumbuh. Berdasarkan latar belakang tersebut diperlukan analisis lebih lanjut mengenai peran dan partisipasi masyarakat serta lembaga dalam pengelolaan dan pengembangan ekominawisata Pulau Lusi. Tujuan dari penelitian ini adalah untuk menilai potensi ekominawisata di Pulau Lusi.

Ekosistem mangrove adalah ekosistem yang khas terdapat di sepanjang pantai atau muara sungai yang dipengaruhi oleh pasang surut air laut (Muharam, 2014). Fungsi fisik mangrove adalah menjaga garis pantai, mempercepat perbentukan lahan baru, sebagai pelindung tepi sungai atau pantai. Fungsi biologis mangrove adalah sebagai tempat asuhan dan berkembang biak bagi berbagai jenis udang, ikan dan binatang lain, tempat berlindung bagi sejumlah besar jenis burung, dan habitat bagi berbagai hidupan liar. Sedangkan fungsi komersial mangrove adalah aquaculture (seperti tambak wanamina), rekreasi (wisata), dan penghasil kayu dan kolam garam (Dianawati et al, 2014).

Wanamina adalah integrasi antara budidaya organisme air payau (yaitu bandeng, kepiting dan lainlain) dan mangrove di kolam yang sama (Purwiyanto dan Fitri, 2014). Wanamina merupakan system pengaturan perikanan budidaya dalam pengelolaan perikanan berkelanjutan.

Ekowisata (ecotourism) adalah sebuah pengalaman perjalanan yang mencakup pelestarian lingkungan serta kelestarian penduduk setempat dan budaya (Bickfort et al, 2017). Minawisata adalah pemanfaatan kawasan wisata dengan pengembangan produksi perikanan untuk mencapai ketertarikan masyarakat pengguna akan pengembangan perikanan pada kawasan tersebut (Dermawan, et al, 2012). Ekominawisata adalah aktivitas perjalanan wisata untuk menikmati suasana alami ekosistem mangrove dan sumberdaya ikan di dalamnya secara bertanggung jawab dengan ikut serta menjaga kelestariannya (Prasenja, et al, 2017).

\section{METODE PENELITIAN}

\section{Lokasi Penelitian}

Penelitian dilakukan di lokasi yang paling dekat dengan Pulau Lusi yakni di Dusun Tlocor, Desa Kedung Pandan, Kecamatan Jabon, Kabupaten Sidoarjo, Jawa Timur, dengan letak koordinat 7 34024.1 ${ }^{\circ}$ LS 112 $52^{\prime} 49.7^{0} \mathrm{BT}$.

\section{Kriteria Responden dan Pengumpulan Data Penelitian}

Metode penelitian yang digunakan yaitu gabungan antara metode penelitian kuantitatif dan kualitatif. Metode kuantitatif dilakukan dengan pengambilan data berupa kuisioner. Sedangkan metode kualitiatif dilakukan dengan pengambilan data berupa wawancara, observasi dan dokumentasi. 
Kuisioner diberikan kepada 94 responden berdasarkan metode incidential sampling, responden diberikan kuisioner dengan beberapa pertanyaan terkait kegiatan wisata di Pulau Lusi. Wawancara secara mendalam dilakukan oleh unsur masyarakat yang menangani ekosistem mangrove di Pulau Lusi (Kepala Dusun, dan ketua RT di Kelurahan Kedung Pandan). Data sekunder diperoleh melalui instansi terkait dan bahan pustaka (literatur).

\section{Kriteria Kawasan Dapat Menjadi Kawasan Wisata (Ekowisata)}

Mengacu Tuwo (2011), suatu kawasan dapat dijadikan sebagai kawasan ekowisata apabila memenuhi beberapa kriteria sebagai berikut:

1. Kriteria sosial ekonomi, seperti: penerimaan masyarakat, kesehatan masyarakat, budaya, pendidikan, keamanan, lapangan pekerjaan dan manfaat ekonomi.

2. Kriteria ekologi, seperti: keanekaragaman, keunikan, biota berbahaya, keaslian, karakteristik kawasan, kerawanan bencana dan konservasi.

3. Kriteria penunjang, seperti: aksesibitlitas, infrastruktur air bersih, kondisi infrastruktur listrik dan kelembagaan.

\section{HASIL DAN PEMBAHASAN}

Kondisi sumberdaya alam dan sarana prasarana di Pulau Lusi.

Berdasarkan observasi yang dilakukan di sekitar Pulau Lusi ditemukan beberapa jenis spesies mangrove dengan tingkat kerapatan dan ketebalan mangrove yang baik. Adapun spesies tersebut adalah Acanthus ebracteatus vahl (Jeruju putih), Acanthus ilicifolius L (Jeruju hitam/daruyu/darulu), Acrostichum aureum linn (paku cai/wikakas/paku laut/mangrove varen), Aegiceras floridum (Mange-kasihan/teruntung), Avicennia alba (Api-api), Sonneratia alba (Pidada/ bogem), dan Avicennia marina (Api-api putih). Beberapa satwa ditemukan dikawasan mangrove Pulau Lusi diantaranya jenis mamalia, burung, ikan dan biota laut lainnya. Menurut Prasenja et al, (2017) terdapat 26 jenis burung khas ekosistem mangrove dan darat pulau-pulau kecil di Pulau Lusi.

Pada lokasi penelitian juga ditemukan satu satwa yang dilindungi yaitu Ketam tapak kuda atau biasa disebut Mimi. Penduduk lokal menyebutnya dengan Belangkas (Mimi jantan) dan Mintuna (Mimi betina). Namun demikian biota ini tidak memiliki daya tarik wisata karena tidak semua masyarakat mengetahui jika biota ini adalah satwa yang dilindungi, bahkan satu-satunya biota langka yang dimiliki Pulau Lusi ini terancam keberadaannya karena pemanfaatan untuk konsumsi oleh masyarakat. Apabila tidak dilakukan sosialisasi dan konservasi maka tidak menutup kemungkinan biota tersebut lama kelamaan akan hilang dari habitat mangrove di Pulau Lusi. Pulau
Lusi memiliki sumber air tawar (sumur) dimana ketersediaan air tawar merupakan faktor utama dalam kegiatan wisata.

Pulau lusi sebagai kawasan budidaya dengan sistem wanamina yaitu budidaya penanaman mangrove (wana) dengan budidaya sumber daya ikan (mina). Sehingga selain dapat memberikan manfaat bagi penduduk sekitar hal ini juga dapat menarik wisatawan untuk mendapat edukasi bahwa kegiatan konservasi mangrove dan kegiatan budidaya ramah lingkungan dapat berjalan beriringan dengan hasil panen ikan yang berlimpah meskipun dengan pakan alami. Keindahan objek alam (panorama) yang dimiliki kawasan Pulau Lusi serta sejarah geologi yang menarik dapat menjadi daya tarik dan nilai edukasi tersendiri bagi wisatawan. Berdasarkan hasil observasi dan wawancara dengan nelayan sekitar, tidak ditemukannya biota berbahaya yang dapat mengganggu aktivitas nelayan maupun pengunjung.

Kondisi jalan aspal sepanjang 15 kilometer menuju Dusun Tlocor yang telah dibangun oleh BPLS hingga saat ini dalam kondisi yang masih baik, namun belum dilengkapi dengan drainase dan penerangan jalan sehingga masih terjadi genangan ketika hujan deras. Selain membangun jalan tlocor, BPLS juga membangun 2 dermaga, yaitu dermaga permanen yang terbuat dari beton di Tlocor dan dermaga semi permanen yang terbuat dari kayu di Pulau Lusi. Jenis transportasi menuju Pulau Lusi menggunakan perahu motor dari dermaga Tlocor dengan jarak 3,16 km (Gambar 1.). Beberapa sarana prasarana penunjang lainnya telah dibangun oleh KKP di Pulau Lusi, diantaranya adalah tempat parkir, panggung, tugu aku cinta lingkungan, toilet umum, gazebo, IPAS, menara pandang, wahana sepeda air, tracking mangrove dan jalur pedestrian.

Berdasarkan analisis kriteria ekologi kondisi sumber daya alam di Pulau Lusi sesuai atau layak untuk dimanfaatkan sebagai kawasan ekominawisata mangrove. Meskipun masih perlu adanya penambahan seperti menambah keanekaragaman mangrove dan penangkaran satwa, terutama untuk satwa yang dilindungi agar menjadikan ekosistem lebih baik.

\section{Kondisi Sosial Ekonomi Masyarakat di kawasan Pulau Lumpur Sidoarjo.}

Kabupaten Sidoarjo merupakan satu-satunya kabupaten di Jawa Timur yang terletak diantara dua sungai besar yakni Sungai Porong dan $(47 \mathrm{~km})$ dan Sungai Surabaya $(32,5 \mathrm{~km})$. Secara geografis letak Kabupaten Sidoarjo adalah antara $112,5^{\circ}-112,9^{\circ}$ BT dan $7,3^{\circ}-7,5^{\circ}$ LS. Secara administratif Kabupaten Sidoarjo terbagi atas 18 kecamatan, 322 Desa dan 31 kelurahan. Luas wilayah Kabupaten Sidoarjo adalah 71.424 ha.

Dusun Tlocor terletak di Desa Kedungpandan, Kecamatan Jabon, Kabupaten Sidoarjo, Provinsi Jawa Timur. Desa Kedung Pandan terdiri dari 5 Rukun Warga (RW), 16 Rukun Tetangga (RT) dan 3 Dusun yaitu Dusun Tlocor, Limbe dan Kedung Pandan. 


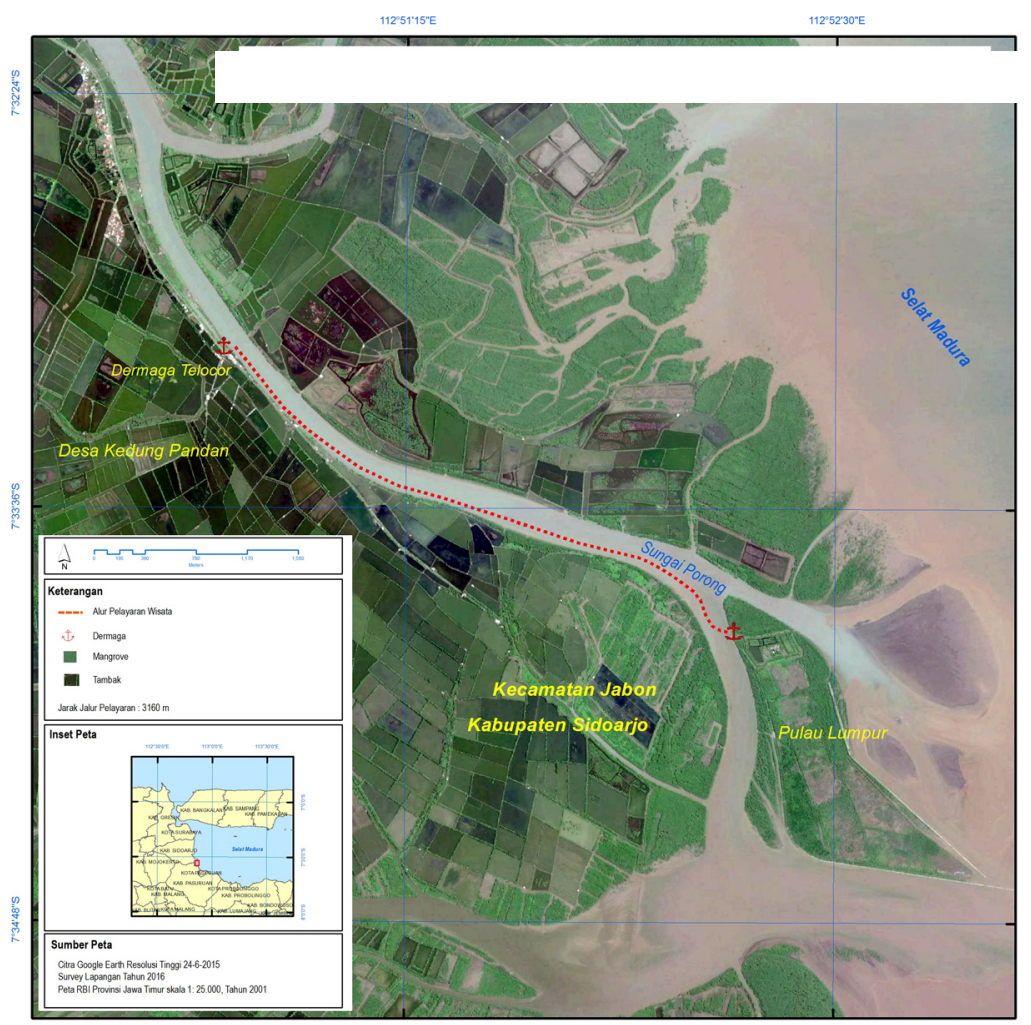

Gambar 1. Peta Aksesbilitas di Pulau Lusi Desa Kedung Pandan, Kecamatan Jabon, Kabupaten Sidoarjo

Berdasarkan data BPS Kecamatan Jabon dalam angka tahun 2015, Desa Kedung Pandan memiliki luas 1.723 hektar. Dusun Tlocor yang terletak di sebelah Tenggara Kabupaten Sidoarjo dan berbatasan langsung dengan Kecamatan Bangil Kabupaten Pasuruan merupakan daerah terpencil sebelum terjadinya bencana semburan dan luapan lumpur panas di Kabupaten Sidoarjo, dengan luas wilayah 15 ha. Menurut kepala dusun Tlocor, jumlah penduduk dusun ini adalah sebanyak 675 jiwa yang terdiri atas 355 jiwa berjenis kelamin laki-laki dan 320 jiwa berjenis kelamin perempuan.

Tabel 1. Data Geografis Dusun Tlocor

\begin{tabular}{|c|c|c|}
\hline No & Jenis Data Geografis & Satuan \\
\hline & Luas wilayah & 15 ha \\
\hline & $\begin{array}{l}\text { Ketinggian tanah dari permukaan } \\
\text { laut }\end{array}$ & $+/-2 \mathrm{~m}$ \\
\hline & Suhu udara rata-rata & $29^{\circ} \mathrm{C}$ \\
\hline & $\begin{array}{l}\text { a. Jarak dari pusat pemerintahan } \\
\text { kelurahan }\end{array}$ & $1 \mathrm{~km}$ \\
\hline & $\begin{array}{l}\text { b. Jarak dari pusat pemerintahan } \\
\text { kecamatan }\end{array}$ & $15 \mathrm{~km}$ \\
\hline & c. Jarak dari ibukota kota & $23 \mathrm{~km}$ \\
\hline & $\begin{array}{l}\text { d. Jarak dari Ibukota Provinsi Jawa } \\
\text { Timur }\end{array}$ & $55 \mathrm{~km}$ \\
\hline & e. Jarak dari ibukota Negara & $944 \mathrm{~km}$ \\
\hline & Banyak curah hujan & $\begin{array}{l}+/-301 \\
\mathrm{Mm} / \mathrm{th}\end{array}$ \\
\hline
\end{tabular}

Sumber: monografi Kelurahan Kedungpandan
Dalam pengembangan suatu kawasan pesisir dan laut menjadi kawasan wisata, kondisi sosial ekonomi masyarakat merupakan salah satu aspek yang akan mendukung pengelolaan suatu kawasan menjadi kawasan wisata. Hal ini dapat dinilai dari tingkat penerimaan masyarakat, tingkat pendidikan dan lapangan pekerjaan/mata pencaharian masyarakat,

Sebagian besar masyarakat setuju atas rencana pengembangan wisata, masyarakat berminat terlibat dalam kegiatan wisata dan berharap kegiatan tersebut benar terealisasi meskipun sebagian besar masyarakat belum bahkan tidak memahami tentang ekominawisata. Pendidikan merupakan faktor yang perlu dipertimbangkan dalam pengembangan wisata. Berikut adalah hasil distribusi responden berdasarkan Tingkat Pendidikan (Tabel 2.).

Tabel 2. Distribusi Responden Berdasarkan Tingkat Pendidikan

\begin{tabular}{llcc}
\hline No & Pendidikan & $\begin{array}{c}\text { Total } \\
\text { Responden }\end{array}$ & Persentase \\
\hline 1 & SD & 9 & $9,57 \%$ \\
2 & SMP & 49 & 52,13 \\
3 & SMA & 30 & 31,91 \\
4 & Diploma/Sarjana & 6 & $6,38 \%$ \\
\hline
\end{tabular}

Sumber: Hasil analisis

Tingkat pendidikan formal responden tergolong cukup rendah. Sebagian besar tingkat pendidikan responden adalah tamatan SMP dan SMA dengan 
prosentase masing-masing 52,13\% dan 31,91\%. Tingkat pendidikan responden yang masih rendah, menjadi motivasi masyarakat untuk ikut berpartisipasi dalam kegiatan pengelolaan wisata Pulau Lusi.

Tabel 3. Distribusi Responden Berdasarkan Mata Pencaharian

\begin{tabular}{clcc}
\hline No & Mata Pencaharian & $\begin{array}{c}\text { Total } \\
\text { Responden }\end{array}$ & Persentase \\
\hline 1 & Petambak & 5 & $5,32 \%$ \\
2 & Petani & 3 & $3,19 \%$ \\
3 & Buruh tani/tambak & 28 & $26,60 \%$ \\
4 & Guru & 6 & $6,38 \%$ \\
5 & Swasta & 13 & $13,83 \%$ \\
6 & Pedagang & 17 & $18,09 \%$ \\
7 & Nelayan & 22 & $23,40 \%$ \\
\hline
\end{tabular}

Sumber: Hasil analisis

Tingkat pendidikan masyarakat akan berpengaruh pada mata pencaharian masyarakat. Hal ini dapat terlihat mata pencaharian sebagian besar responden (Tabel 3.) sebagai buruh tani/tambak, yaitu 26,60\% dan nelayan sebanyak 23,40\%. Maka dapat disimpulkan bahwa rendahnya tingkat pendidikan berpengaruh pada keterbatasan keterampilan dan pengetahuan sehingga masyarakat tidak dapat bersaing untuk mendapatkan pekerjaan yang lebih baik.

Tabel 4. Distribusi Responden Berdasarkan Tingkat Pendapatan

\begin{tabular}{cccc}
\hline No & $\begin{array}{c}\text { Tingkat Pendapatan } \\
(\mathrm{Rp})\end{array}$ & $\begin{array}{c}\text { Total } \\
\text { Responden }\end{array}$ & Pesentase \\
\hline 1 & $500.000-1.000 .000$ & 19 & $20,21 \%$ \\
2 & $1.000 .000-1.500 .000$ & 23 & $24,47 \%$ \\
3 & $1.500 .000-2.000 .000$ & 21 & $22,34 \%$ \\
4 & $2.000 .000-2.500 .000$ & 17 & $18,09 \%$ \\
5 & $2.500 .000-3.000 .000$ & 10 & $10,64 \%$ \\
6 & $>3.000 .000$ & 4 & $4,26 \%$ \\
\hline
\end{tabular}

Sumber: Hasil analisis

Pendapatan merupakan salah satu indikator dalam pengukuran tingkat kesejahteraan ekonomi seseorang atau masyarakat. Pada umumnya tingkat pendapatan akan berkorelasi dengan tingkat pendidikan. Semakin rendah tingkat pendidikan maka tingkat pendapatan pun akan rendah. Secara keseluruhan, dominan responden sebanyak 42 orang hanya mampu memperoleh pendapatan per bulan kurang dari Rp. 1.500.000/bulan dengan latar belakang pendidikan rata-rata SMP.

Berdasarkan Tabel 4. menunjukkan bahwa ratarata pendapatan di Dusun Tlocor sangatlah rendah bila dibandingkan dengan UMK Kabupaten Sidoarjo tahun 2016 yang berkisar pada angka Rp. 3.040.000/ bulan. Oleh karena itu diperlukan mata pencaharian alternatif agar dapat menurunkan angka kesenjangan pada tingkat pendapatan.
Pengembangan mata pencaharian alternatif perlu mendapat perhatian karena sumberdaya pesisir dan perikanan saat ini telah banyak mengalami tekanan dan degradasi. Pengembangan mata pencaharian alternatif tidak hanya dalam bidang perikanan seperti pengolahan, pemasaran atau budidaya ikan tetapi juga dalam kegiatan non perikanan seperti dalam bidang pariwisata. Dengan adanya rencana pengelolaan Pulau Lumpur menjadi kawasan ekominawisata diharapkan dapat tercipta mata pencaharian alternatif bagi masyarakat Dusun Tlocor. Sehingga, ketimpangan ekonomi yang terjadi saat ini dapat teratasi dan kondisi sosial masyarakat Dusun Tlocor menjadi lebih baik.

\section{Peran dan partisipasi masyarakat serta lembaga dalam pengelolaan dan pengembangan ekominawisata Pulau Lusi.}

Berdasarkan latar belakang pendidikan, sebagian masyarakat di Dusun Tlocor secara umum kurang mendukung dalam kegiatan wisata dan upaya pengembangan wisata. Masyarakat menyadari bahwa mereka tidak memiliki keterampilan dan keahlian serta pengalaman yang dapat mendukung kegiatan wisata. Ada beberapa masyarakat yang mengaku memiliki keterampilan, seperti menanam mangrove, budidaya ikan dan sebagai operator speed boat.

Meski demikian, sikap penerimaan masyarakat merupakan modal dasar untuk mencapai tujuan utama wisata mangrove yaitu untuk meningkatkan kesejahteraan masyarakat lokal dan sekaligus menjaga kelestarian mangrove. Selain itu pelibatan masyarakat lokal merupakan sebuah pengamanan sosial untuk kawasan ekowisata dari ancaman luar kawasan (Hitchner, et al, 2009) tanpa adanya persetujuan dan keterlibatan masyarakat lokal, kegiatan wisata tidak mungkin bisa terealisasi. Penduduk lokal dan lingkungannya merupakan suatu kesatuan wilayah wisata. Hal tersebut merupakan potensi peluang yang perlu dipertahankan dan dikembangkan partisipasinya untuk memperoleh manfaat agar tercipta insentif dan motivasi untuk ikut menjaga lingkungannya, terutama ikut mengkonservasi mangrove di Pulau Lusi.

Pengelolaan ekominawisata Pulau Lusi melibatkan 4 (empat) stakeholder, yaitu: KKP, PEMDA, Masyarakat dan CSR yang mempunyai hubungan saling mempengaruhi.

1. Kementerian Kelautan dan Perikanan (KKP).

KKP bertanggung jawab dalam memberikan edukasi dan sosialisasi baik kepada pemerintah daerah, kelompok masyarakat dan kepada stakeholder lain yang ikut terlibat dalam pengelolaan ekominawisata Pulau Lusi serta melakukan promosi baik melalui media cetak maupun elektronik. Manfaat yang diperoleh dari kegiatan ini adalah ikut serta dalam meningkatkan pelestarian lingkungan, pelestarian budaya, 
Penerimaan Negara Bukan Pajak (PNBP), dan publikasi kegiatan KKP.

2. PEMDA.

Dalam pengelolaan ekominawisata Pulau Lusi, pemerintah daerah bertanggung jawab dalam memberikan edukasi dan sosialisasi kepada masyarakat sekitar pulau, masyarakat Kabupaten Sidoarjo maupun kepada stakeholder lain, serta melakukan promosi baik melalui media cetak maupun elektronik. Manfaat diperoleh dari kegiatan ini adalah pelestarian lingkungan, pelestarian budaya, penerimaan pajak dan publikasi daerah.

3. Masyarakat.

Peranan masyarakat dalam pengelolaan ekominawisata mangrove sangatlah penting, karena masyarakat yang nantinya akan berinteraksi langsung dengan para wisatawan yang berkunjung ke Pulau Lusi. Adapun peran serta masyarakat dalam pengelolaan ini yaitu sebagai operator transportasi, pemandu wisata dan pedagang. Manfaat yang akan diperoleh adalah adanya pemberdayaan masyarakat dan peningkatan kapasitas ekonomi, sosial maupun lingkungan.

4. CSR.

Stakeholder yang berasal dari tindakan yang dilakukan oleh perusahaan sebagai rasa tanggung perusahaan terhadap sosial maupun lingkungan. Dalam kaitannya dengan pengelolaan Pulau Lusi kegiatan yang dapat dilakukan melalui CSR yaitu edukasi dan promosi serta adopsi mangrove. Manfaat yang akan diperoleh stakeholder dari kegiatan ini adalah ikut serta dalam melestarikan lingkungan, melestarikan budaya dan publikasi kegiatan CSR perusahaan.
Dalam pengelolaan ekominawisata selain adanya dukungan dari stakeholder, dukungan kelembagaan merupakan salah satu aspek penting yang akan mempengaruhi tingkat keberhasilan pelaksanaannya. Dukungan kelembagaan pemerintah yang terkait dengan perencanaan pengembangan wisata mangrove sangat baik, yaitu adanya UU no 1 tahun 2014 tentang perubahan atas undang-undang No 27 tahun 2007 tentang pengelolaan wilayah pesisir dan pulau-pulau kecil, Perpres nomor 73 tahun 2012 tentang strategi nasional pengelolaan ekosistem mangrove, dan Perda no. 6 tahun 2012 tentang pengelolaan dan rencana zonasi wilayah pesisir dan pulau-pulau kecil tahun 2012-2032.

Partisipasi masyarakat serta lembaga memainkan peran penting dalam pengelolaan dan pengembangan ekominawisata mangrove. Inisiatif dan partisipasi masyarakat dapat memobilisasi dan mengorganisir mereka untuk melakukan tindakan kolektif dalam pengelolaan ekominawisata mangrove yang berkelanjutan. Keterlibatan masyarakat dalam pembibitan mangrove dan ekominawisata merupakan indikasi lain pengembangan kapasitas masyarakat. Ini bertujuan untuk mengembangkan dukungan yang kuat terhadap pengelolaan mangrove yang berkelanjutan dan memperbaiki sarana penghidupan bagi masyarakat setempat sehingga dapat mengurangi tekanan pada hutan mangrove. Bentuk partisipasi yang dilakukan oleh masyarakat dalam pengelolaan dan pengembangan ekominawisata mangrove adalah dengan menjadi aktor pariwisata baik di dalam maupun di luar kawasan Pulau Lusi.

Bentuk-bentuk partisipasi masyarakat dapat berupa penyedia pusat informasi pengunjung, pelayanan jasa,
STAKEHOLDER

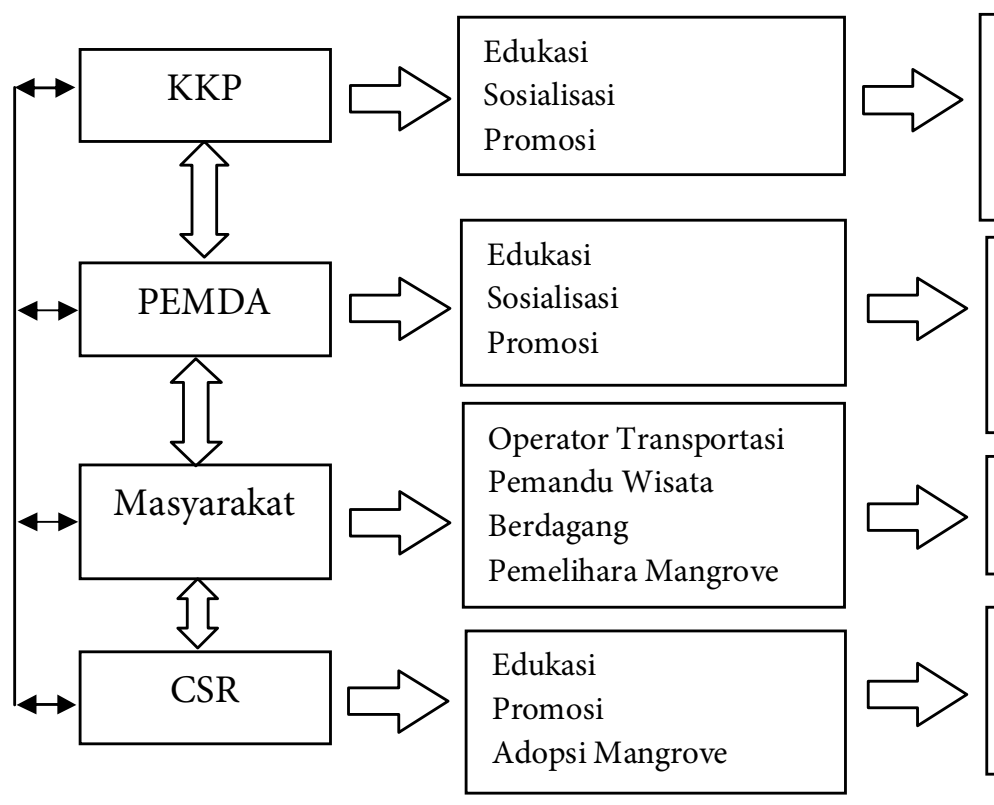

MANFAAT

Pelestarian Lingkungan

Pelestarian Budaya

PNBP

Publikasi

Pelestarian Lingkungan

Pelestarian Budaya

Penerimaan Pajak

Publikasi

Pemberdayaan

Peningkatan Kapasitas

Pelestarian Lingkungan

Pelestarian Budaya

Publikasi

Gambar 2. Diagram Pengelolaan Ekominawisata Mangrove di Pulau Lusi. 
penyediaan sarana dan prasarana (parkir, penginapan dan transportasi ke pulau), pembibitan dan penanaman mangrove, pemeliharaan sarana dan prasana yang sudah tersedia di pulau, dan membangun toko atau warung untuk menjual makanan, minuman, dan souvenir. Sehingga dari bentuk partisipasi yang dilakukan di sektor pariwisata yang sangat menjanjikan ini nantinya akan berakibat pada bertambahnya kesempatan kerja dan berarti mampu menaikkan serta menghasilkan pendapatan dan menjadi sumber dana bagi suatu daerah dan masyarakat di kawasan Pulau Lusi.

Secara umum keterampilan dan pengalaman yang dimiliki masyarakat Tlocor saat ini kurang mendukung untuk pengembangan kegiatan ekominawisata mangrove. Oleh karenanya diperlukan adanya upaya pengembangan keterampilan dan kemampuan masyarakat melalui upaya pendidikan non formal seperti pelatihan dan pendampingan dalam ragam kegiatan ekonomi jasa wisata. Kelompok masyarakat yang sudah terbentuk perlu diberikan penguatan kelembagaan dan keterampilan sehingga dapat dilibatkan dalam pengelolaan ekominawisata di Pulau Lusi.

Kelembagaan masyarakat saat ini masih berupa wadah untuk menyampaikan aspirasinya atau semacam bentuk eksistensi masyarakat terhadap lingkungan sekitar, seperti pokmaswas dan jemaah tahlil. Sedangkan untuk keperluan penanganan wisata, stakeholder akan membentuk badan pengelola dengan pengesahan Notaris atau Kepala Desa yang berperan untuk mengelola dan mengawasi semua aktivitas dilapangan. Badan pengelola adalah unsur pelaksana teknis dalam pengelolaan ekominawisata. Lembaga ini diketuai dan beranggotakan masyarakat, sedangkan KKP dan Pemerintah Daerah sebagai pemangku kebijakan, pembina, pengawas dan penanggung jawab.

\section{KESIMPULAN}

Peran dan partisipasi masyarakat serta lembaga dalam pengelolaan ekominawisata mangrove sangat penting untuk mencapai ekominawisata yang berkelanjutan. Partisipasi masyarakat merupakan peluang yang perlu dipertahankan dan dikembangkan partisipasinya untuk memperoleh manfaat agar tercipta insentifdan motivasi untukikut menjaga lingkungannya, terutama ikut mengkonservasi mangrove di Pulau Lusi.

\section{UCAPAN TERIMAKASIH}

Ucapan terima kasih disampaikan kepada Ir. Elvita Nezon, MM atas dukungan moral dan material, Nanda Dharma Perdana, Firdaus Wajidi dan Wahyu Aditya Nugraha atas bantuan penyelesaian penelitian ini.

\section{DAFTAR PUSTAKA}

Apriana E. 2015. Kearifan lokal masyarakat aceh dalam konservasi laut. J. Biologi Edukasi,7(1): 47-55.

Bickford N, Lindsey S, Sonja B, Matthew RB and Dustin HR. 2017. Evaluating the role CSR and SLO in ecotourism: collaboration for economic and environmental sustainability of Arctic resources. J. Resources, 6(21): 1-9.

BPLS dan BPOL. 2012. Studi penanganan kawasan sekitar muara kali Porong. Laporan Akhir. Surabaya.

Dermawan A dan Aziz AM. (2012). Pengembangan minawisata pulau-pulau kecil untuk mendukung implementasi Blue Economy. Paper Konas VIII Pengelolaan Pesisir, Laut dan Pulau-Pulau Kecil. Mataram, 22- 24 Oktober 2012.

Dianawati L, Suratman dan Su RH. 2014. Kajian peran lembaga dan kearifan masyarakat dalam pengelolaan ekosistem hutan mangrove secara terpadu di Delta Mahakam. J. Majalah Geografi Indonesia, 28(1): 81-95.

Faturrohmah S dan Bramantyo M. 2017. Identifikasi dinamika spasial sumberdaya mangrove di wilayah pesisir Kabupaten Demak Jawa Tengah. J. Majalah Geografi Indonesia, 31(1): 56-64.

Hidayah Z dan Dwi BW. 2013. Analisa temporal perubahan luas hutan mangrove di Kabupaten Sidoarjo dengan memanfaatkan data citra satelit. J. Bumi Lestari,13(2): 318-326.

Hitchner SL, Florence LA, Lian T, Supang G, Sinah NA, and Ellyas Y. 2009. Community-based transboundary ecotourism in the heart of Borneo: A case study of The Kelabit Highlands of Malaysia and The Kerayan Highlands of Indonesia. J. of Ecotourism. 8(2):193-213.

Laporan Penyelenggaraan Pemerintah Daerah Kabupaten Sidoarjo Tahun 2014

Muharam. 2014. Penanaman mangrove sebagai salah satu upaya rehabilitasi lahan dan lingkungan di kawasan pesisir pantai utara Kabupaten Karawang. J. Ilmiah Solusi, 1(1):1-14.

Mulyo, ATJ. 2015. Analisis kesesuaian ekosistem mangrove untuk kegiatan wisata mangrove di Pulau Tanjung Lumpur, Kabupaten Sidoarjo. Tesis. Universitas Padjajaran Bandung. 145hlm.

Prasenja, Y, Abimanyu TA dan Dietrich BG. 2017. Analisis keberlanjutan ekosistem mangrove untuk kegiatan ekominawisata di Pulau Lumpur Sidoarjo. J. Ilmu dan Teknologi Kelautan Tropis,9(1): 175184.

Purwiyanto AIS dan Fitri A. 2014. Effect of silvofishery on ponds nutrient levels. Jurnal Ilmu Kelautan, 19(2): 81-87 